\section{International Journal of Research in Social Science and Humanities (IJRSS)}

DOI: https://doi.org/10.47505/IJRSS.2021.9168
E-ISSN : 2582-6220

Volume 2, No. 2

Mar - Apr - 2021

\title{
Geospatial Surface Area Mapping of Bokkos Local Government Area (LGA) of Plateau State of Nigeria
}

\author{
Joshua Yohanna Gwanshak ${ }^{1}$ and Emmanuel Samuel Danbauchi \\ ${ }^{1}$ Department of Geography, Faculty of Natural and Applied Sciences \\ Plateau State University Bokkos, Plateau State, Nigeria \\ ${ }^{2}$ Department of Geography \\ University of Abuja, Nigeria
}

\begin{abstract}
The study is a geospatial surface area mapping of Bokkos LGA physical features through the aid of geographic information system (GIS) application that was used to analyze surface conditions plotted from reported data which dwell the contour, slope, aspect, curvature and hill shade maps as well as a land-use map. The morphometric parameters were derived from the Digital Elevation Model (DEM) using ArcGIS. The result revealed 433 contours with 100m intervals with less around Kwatas, Bokkos, and Butura and very high around Mushere west and central. The slope was very high around Mushere west/ central, Mangar/Damwai, Dafffo, Sha and Mangunahave moderate slope. In areas of Mushere, Mangar and Damwai runoff was high, soil erosion indicated sign of very high adverse effects on the environment. Aspect revealed red colour, North, orange Northeast and yellow colour tilt to the east while the green southeast. Hillshade was observed lesser in Mushere west/central, Damwai with a curvature map for soil erosion patterns and Vegetation covers were predominant certain areas of Bokkos and the study gave appropriate recommendation to agency concerned.
\end{abstract}

Keywords: Bokkos, Geospatial, GIS, Mapping.

\section{INTRODUCTION}

Bokkos Local Government Area (LGA) is one out of the $17^{\text {th }}$ LGAs of Plateau state in Nigeria which is located between $9^{0} 18^{0} 0 \mathrm{~N}$ and $9^{0} 0^{0} 00 \mathrm{E}$ of the Northern Tropical region of about latitude $15^{0}-30^{0}$ North and South, East of the Equator, about 77 Kilometres South of Jos, the capital State. It is bounded to the North by Barkin Ladi, to South by Qua'an Pan, to the East by Mangu LGA and West by Sanga LGC of Kaduna State. With a population of 178,454 people according to NPC, 2016 and has a Landmass of about 3,053 square Kilometres. The major tribes make up the population of Bokkos are Ron, Kulere and Mushere who inhabit the thirteen districts of the local government. The geology of the Jos Plateau is part of the Precambrian to Mid Cambrian and Jurassic Northern Nigerian Crystalline shield (Diary of Plateau State, 2002; Schoneich and Mbonu, 1991).The elevation of the Jos Plateau is purported to have occurred about 570 million years ago with the latest occurring 500 thousand years ago due to tectonic upheaval which was followed by gradual denudation in which the whole of Jos plateau became eroded. The denudation is evidenced in the relief of the whole of Jos Plateau with Bokkos inclusive. 
International Journal of Research in Social Science and Humanities (IJRSS), Vol. 2, No. 2, Mar-Apr - 2021

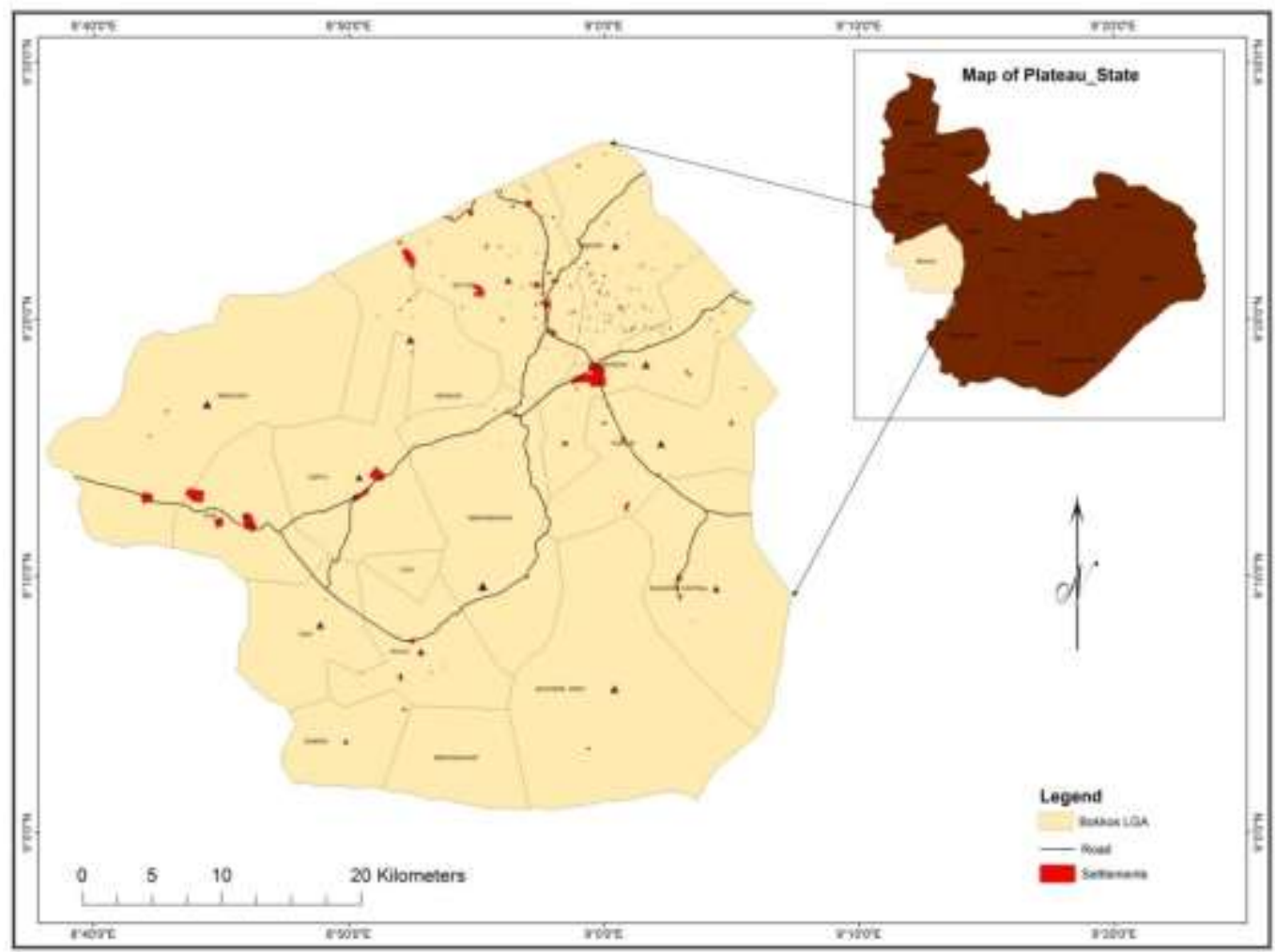

Figure 1 Geospatial Map of Bokkos Local Government Area [LGA) of Plateau State

The relief of Bokkos falls under the Manguna hills and is heavily characterized by dissecting rocky hills and hillocks including few Messa hills and inselbergs of post Jurassic (Mid cretaceous age) which are characteristic of areas in the south-western isostatic plateau escarpment (Schoeneich and Mbonu, 1991). The Manguna hills which Mahurum is part of are said to be as high as Shere Hills which are located north-east of Jos (Mangut, 2006). 
Bokkos is not markedly different especially from that of areas within the south western part of the Jos Plateau escarpment though there are slight variations. Generally, the Jos Plateau normally records temperatures between mean annual temperatures of $21.6^{\circ} \mathrm{c}$, mean monthly minimum of $19.7^{\circ} \mathrm{c}$ in January, and mean monthly maximum of $24.3^{\circ} \mathrm{c}$ in April (Schoneich and Mbonu 1991). This makes the area cooler than most areas at lower elevations. Annual rainfall can be up to $1500 \mathrm{~mm}$ (Roder 2008).This weather pattern is high influenced by the geological elevation of the Jos plateau which stands at 1250m (about $4100 \mathrm{ft}$ ) above sea level (Shaw 1978; Roder 2008; Schoneich and Mbonu 1991). Thus, the Orographical advantage of the Jos Plateau induces high rate of precipitation and condensation in form of rain, dew and fog. Rainfall averaging 1500mm-2000mm is experienced in the area every year (Hossan, 1986; Ajeagbu, Adeptu and Ajakpo, 1992). Harmattan which is characteristic of the dry season normally occurs around November and terminates mostly around late February.

The soils of the Jos Plateau are said to be the product of the "interaction of pedogenic factors (climate, biota parent material, topography and time) which has produced a series of soils that reflect the particular influence of parent material (in terms of texture and nutrient status) and topography in terms of drainage" (Ajeagbu, Adeptu and Ajakpo, 1992). Based on observation, the soil of the area supports the cultivation of a variety of crops like, Irish potatoes, Acha also known as hungry rice, (Muar), Cocoyam, garden egg, pepper Capsicum Frutensis, different species of native bean, Sweet potatoes, Sesame, Livingstone potato, finger millet and many others. The cultivation of some of these crops is said to date back to antiquity while others were recently introduced. Thus, the cultivation of such varieties of crops might be due to the fertility of the soil. Most of the farms in the Bokkos area are in the plains but in ancient times, farms and gardens were mostly maintained within hill dwelling enclaves (Maram, 2014). Therefore, fertile soil and other factors like presence of different games and the elevation of the hills which served as natural fortifications might have been the major attraction for the peopling of the area right from period of antiquity (Maram, 2008).

Geospatial data is data about objects, events, or phenomena that have a location on the surface of the earth, including location information (usually coordinates on the earth), attribute information (the characteristics of the object, event, or phenomena concerned), and often also temporal information (Kristin and Han, 2016). Geospatial surface area mapping of Bokkos LGA shows the physical features through the aid of geographic information system (GIS) application. This software application capturing, storing, manipulating, analyzing, modelling and displaying information about the surface of the earth, and the phenomena distributed on it. GIS typically deals with information that is geographically or spatially explicitly, representing the spatial variation of phenomena over the earth. Representation of maps as layers' data can be performed and studied by GIS. Surface analysis will depict surface conditions plotted from reported data or generated by computer models. Surface analyst in GIS generated the contour, slope, aspect, and hill shade maps. 3D Analyst in GIS environment can create new surfaces from existing data sets. These surfaces as regularly spaced grids or as triangulated irregular networks (TINs). Once the surface data has been created it can be used for further analysis including enhanced geo-visualization, such as creating a shaded relief, or for more advanced analysis such as determining the visibility from a specific position or route. Available surface analysis tools include hillshade, slope, aspect, curvature, cut/fill, view shed, visibility observer points and contours with barriers. This study focus on generation of contour map, slope map, aspect map, hillshade map and curvature map using 3D - Analyst tool in GIS environment and land use through GIS classification tool. Thus, to ascertain the elevation of the surface area a digital elevation model was applied to depict the surface area elevation of Bokkos LGA.

\section{METHODOLOGY}

The study was specific descriptive design where geospatial data that were gathered at some stage in field validation exercise and generated of data from satellite imageries. Step by step processes involve of GIS application of pre-processing and post processing using IDRISSI software. Feature extraction from topographic/administrative maps and remotely sensed data were done using ESRI ArcGIS software and Geospatial data standardization, integration and analysis was carried out in the ArcGIS environment. 3D-Analyst tool was used in Arc GIS 10.4 version to prepare slope map, aspect map, contour map and hillshade map and the detailed procedure was explained in the following subsections. ArcGIS 3D-Analyst is an ArcGIS extension that provides advanced tools for three dimensional geo-visualizations, analysis and surface generation. A better spatial understanding of vector or raster data can use ArcGIS 3D Analyst. In utilizing ArcGIS 3D effectively require use of surface creating, surface analysis and base map preparation that will depict the image creation.

The surface creation enable to the research to create a new surface from already existing data sets which enhances visualization, such as creating a shaded relief, or for more advanced analysis such as determining the visibility from a specific position or route. In the aspect of surface analysis, the new data generated reproduce contour, slope, aspect, hillshade and curvature map. The morphometric parameters (slope angle, aspect, plan and profile curvature) were derived from the Digital Elevation Model (DEM) using Esri ArcGIS. Slope angle (change of the maximum slope), aspect (direction of steepest slope with respect to North), plan 
curvature (intersection between the topographic surface and th plane) and profile curvature (intersection between the topographic surface and the plane parallel to the direction of the maximum slope) maps were obtained for each cell (Bartellett et al, 2017). Plan curvature allows verification of the concavity or convexity of slopes and consequently indicates the convergence or divergence of superficial and sub-surface flow. Curvature describes the change of slope angle affecting flow acceleration and deceleration, which influences erosion and deposition. Positive values indicate that the surface is convex and that flow accelerates, while negative values indicate that the surface is concave and that flow decelerates. By overlaying geology, land use, slope angle, aspect, plan and profile curvature maps with the landslide inventory map, the response to the variation of such environmental parameters was analysed for each landslide source area. Hence, the plotting of the base map of Bokkos through extract from shuttle radar topographic mission (SRTM).

\section{RESULT AND DISCUSSION}

The geospatial maps generated using surface analysis/3D Analyst tool in the GIS environment has been studied and analyzed as seen below:

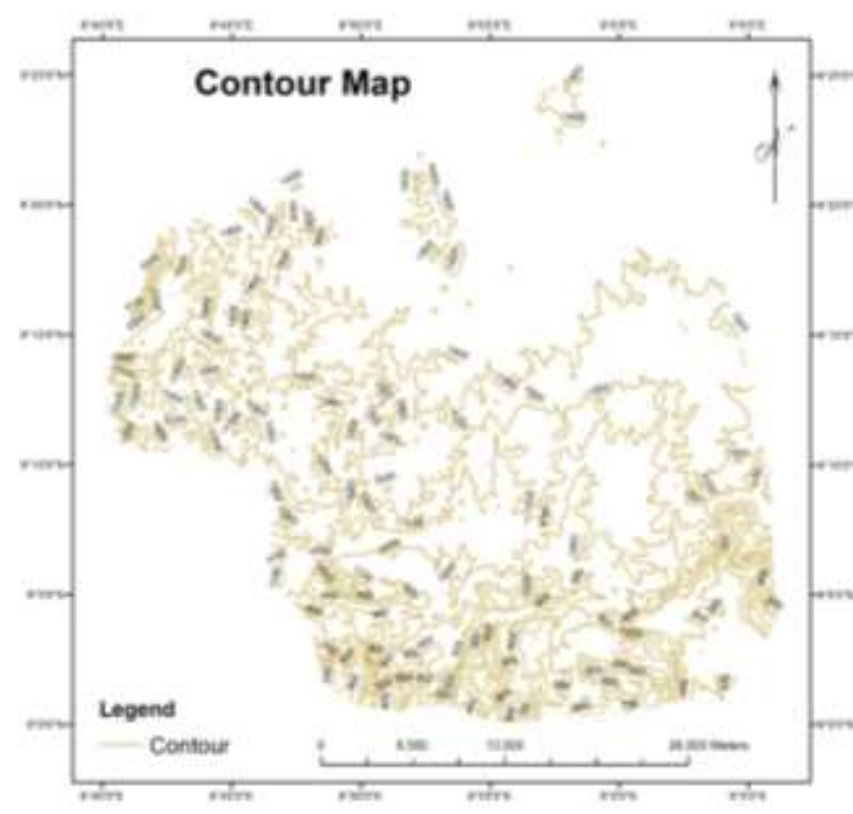

Fig 2 Contour Map

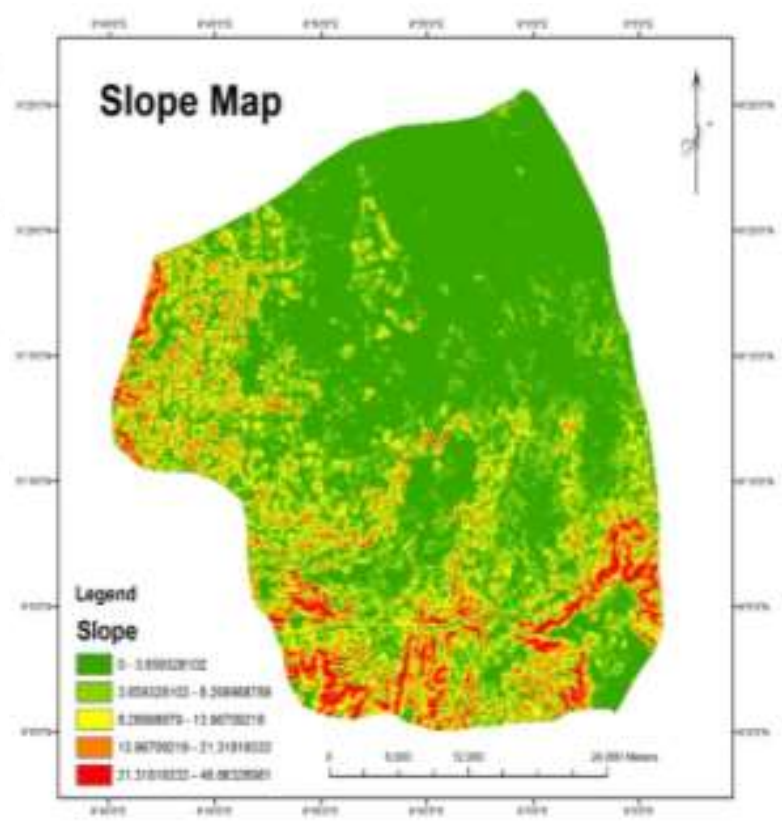

Fig 3 Slop Map

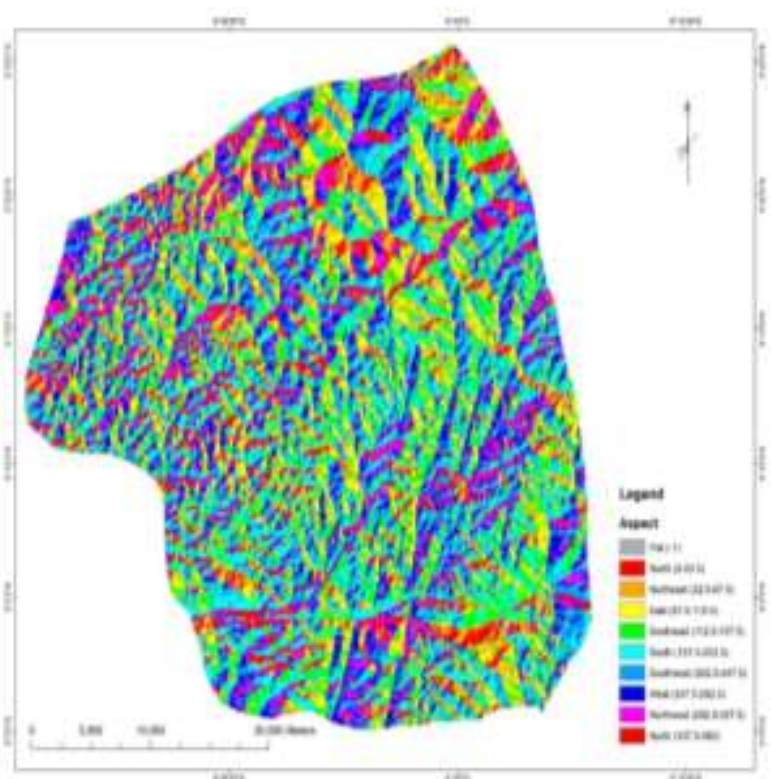

Fig 4 Aspect Map

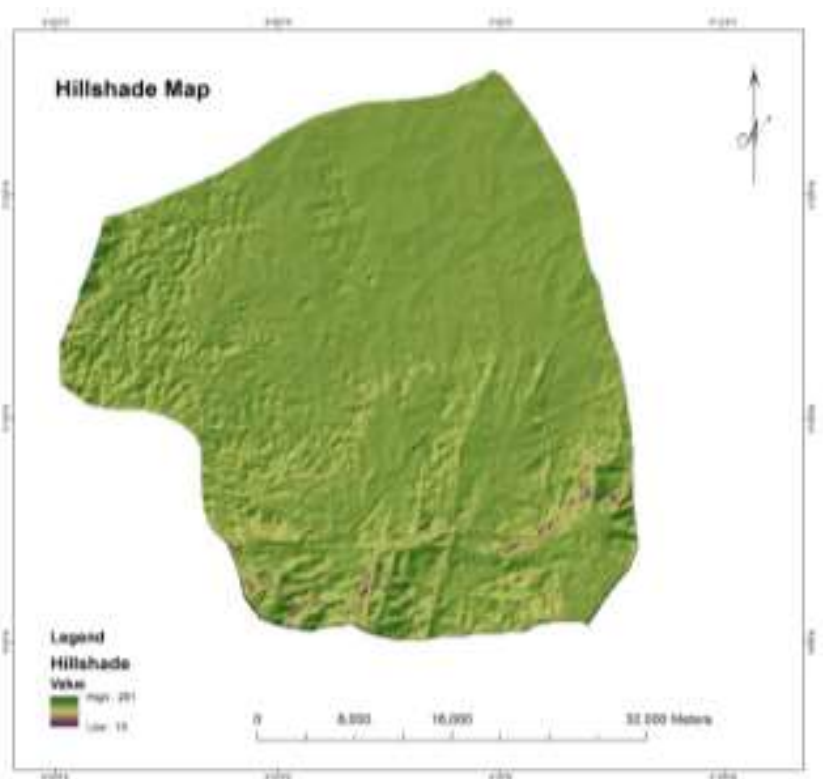

Fig 5 Hillshade Map

Base on Figure 2 that shows contour allows identifies the potential regions where natural disasters like landslides, earthquake, flood and volcanic eruptions can take place. These represent elevated places at regular interval of 100m. The elevations are higher in places around Mushere central/west, Mbar, Damwai, Toff, Richa and Manguna and districts mentioned earlier are higher 
compares to kwatas, Bokkos and Butura. Bokkos LGA contours has the highest figure of elevation of 1400 and lowest figure of elevation as $300 \mathrm{~m}$ which signifies erodibility and runoff processes are much higher in places of high elevation than other location. The slope seen in fig 3 is considered the maximum rate of change from each cell to its neighbours that are described base on angle of gentle slope, moderate slope, steep slope and very steep slope. Bokkos slopes are much in place around Mushere west/central, Mbar, Damwai, Richa, Toff and Manguna. The slopes are gentle, moderate and steep slope. The higher the slope the more the force of erodibility and flow of water, the moderate the slope of a surface the lesser the erodibility and flow of water which occurs in areas like Daffo, Tangur, Shaand Mangor. Whereas part of Tangur, Bokkos, Butura, kwatas has gentle Slope which identifies erosion processes less in those part of Bokkos LGA. It is therefore, as already observed for the Sicily Region (Italy) by Manzo, Tofani, Segoni, Battistini, and Catani (2013), the influence of aspect may be negligible in a landslide susceptibility assessment. Figure 4 revealed a geospatial surface of aspect map of Bokkos that red colour is falling to the North, orange colour is falling towards the Northeast direction, yellow colour tilt to the east, while the green colour is dipping to the southeast. Blue is falling towards the south direction, moorea blue is dwindling towards southwest direction as ultra-blue is falling towards west and pink colour is decreasing towards Northwest. And figure 5 shows hillshade map of Bokkos which are lesser in places like Mushere west/central, Damwai and part of Mbar Districts while areas like Richa, Tangur, Bokkos, Butura, Kwatas, Manguna, Mangor, Sha, Toff have a high hillshade value. Curvature map seen in figure 6 revealed the curvature map of Bokkos which Curvature displays the shape or curvature of the slope. A part of a surface can be concave or convex; at the curvature value. The curvature value can be used to find soil erosion patterns as well as the distribution of water on land. The geospatial surface area of Bokkos displayed recent vegetation from land service (Corpernicus global land service, (2019) Vegatation) as seen figure 7 below. Bokkos' Vegetation covers are predominant in areas such as Mushere west/central, Mbar, Damwai and Manguna as well as areas such as Kwatas, Bokkos, Butura, Daffo and Tangur are occupied by settlements in places built-up areas are Bokkos town, Daffo, and Butura. However, the pictural image of digital elevation map in 2 dimension and 3-dimension

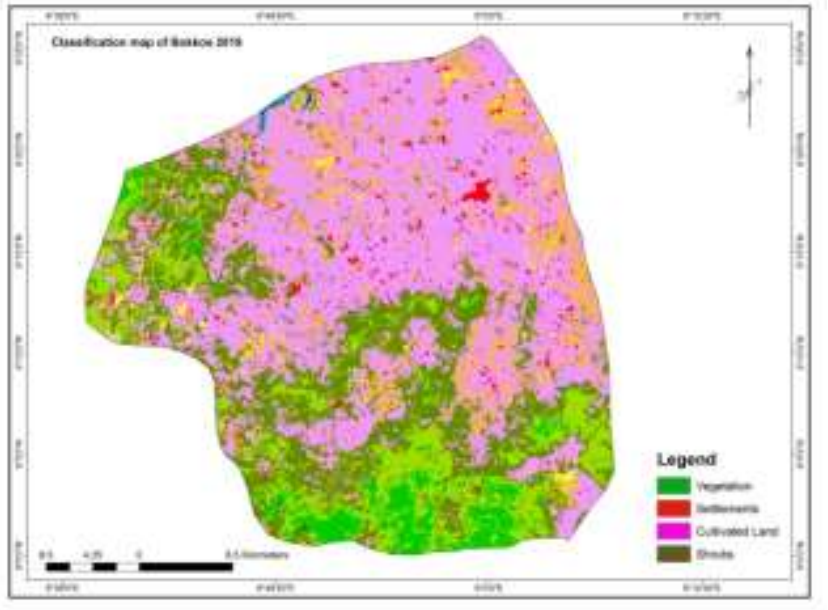

Figure 7 Vegetation cover map

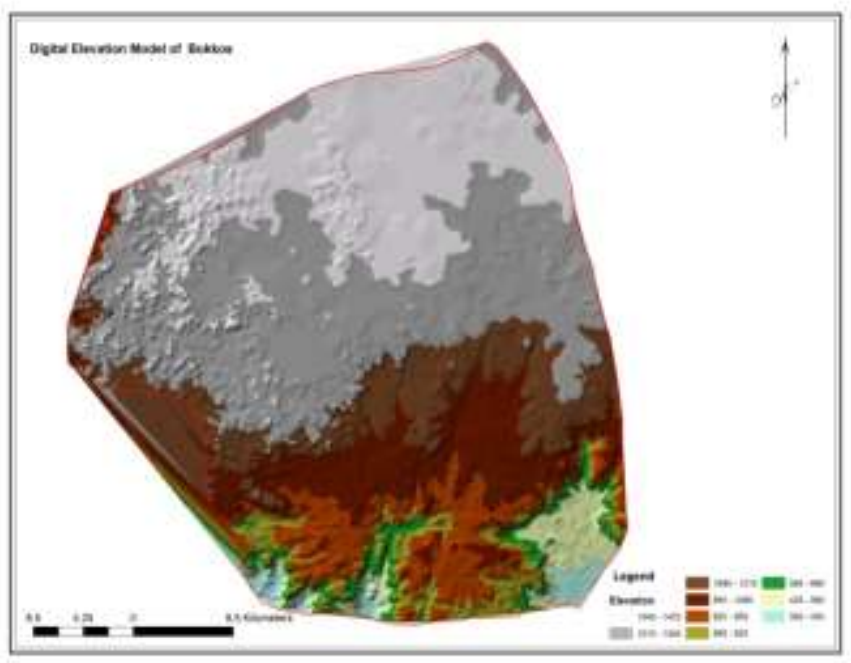

Figure 10 Digital Elevation Model in 2-Dimensional

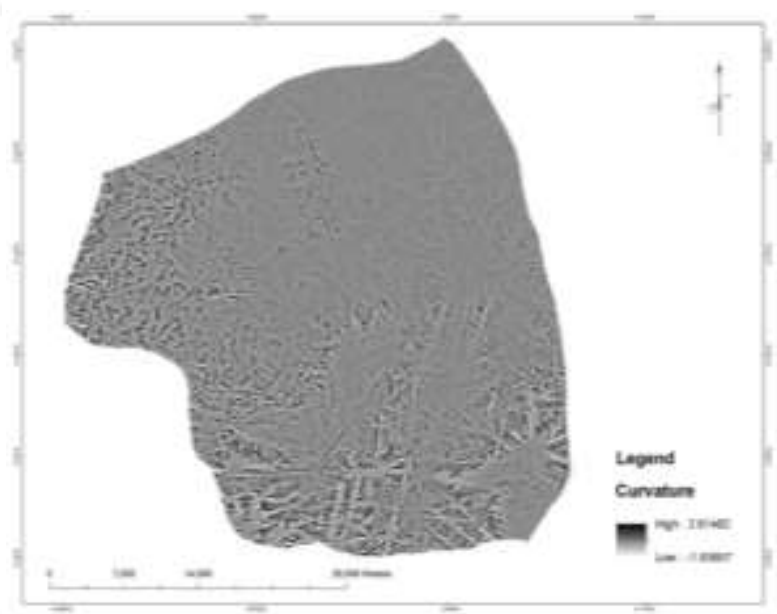

Figure 8 Curvature Map

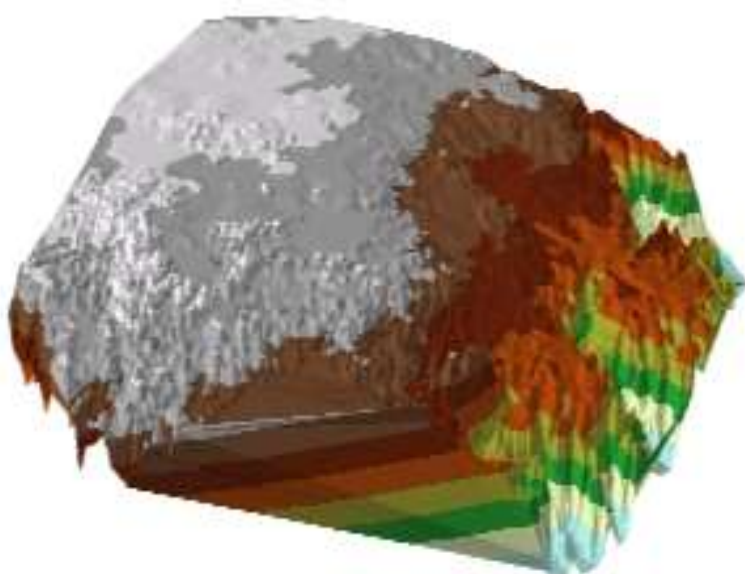

Figure 11 Digital Elevation Model in 3-Dimension 


\section{CONCLUSIONS}

The study of geospatial surface area mapping of Bokkos LGA revealed 433 contours with 100m interval with less around Kwatas, Bokkos and Butura and very high around Mushere west and central. Slope is very high around Mushere west/ central, Mangar/Damwai, Dafffo, Sha and Mangunahave moderate slope. In areas of Mushere, Mangar and Damwai runoff is high, soil erosion indicating sign of very high that might have adverse effects on the environment. This however, necessitates the need for concern agencies to have an environmental impact assessment of the study environment for the benefit of agricultural activities.

\section{REFERENCES}

Ajeagbu, H. I., Adeptu, A. A. and Ajakpo J. E. (1992). Jos Plateau Environmental Excursion Guide. Department of Geography and Planning, University of Jos and Department of Geography, University of Durham, Uk

Bartellett c, Giannecchin R., Avanzi D, Galanti Y,. and Mazzali A., (2017).The influence of geological-morphological and land use settings on shallow landslides in the Pogliaschina T.basin (northern Apennines, Italy). JOURNAL OF MAPS,. VOL. 13, NO. 2, 142-152 http://dx.doi.org/10.1080/17445647.2017.1279082

Hossan, M. T, et al (1986). Half-Day Excursion on the Geology of the Jos Plateau including visits to: Jurassic Younger Granite Ring Complexes, Tertiary-Quaternary Volcanoes. Association of Geophysicists in Exploration and Research in Africa (AGERA), ${ }^{\mathrm{RD}}$ International Conference on Current Research in Geophysics and Geophysical Exploration in Africa, Jos Nigeria

Kristin S and Han G (2016)The Open Geospatial Data Environment School of Engineering and Advanced Technology, Massey University, New Zealand (Albany, Auckland campus)

Mangut, J. (2006) Aspects of Historical Archaeology of the Ron People on the Plateau, Nigeria, Unpublished PhD Thesis, University of Ibadan.

Maram, M. M. (2008). A study of Archaeological Formations in Manguna District, Bokkos LGA, Plateau State. Unpublished BA Thesis, ABU, Zaria.

Roder, W. (2008). "Jos." Microsoft® Encarta® 2009 [DVD], Redmond, WA: Microsoft. Roselyne N, 2014

Schoeneich, K. and Mbonu, W. C. (1991). Excursion Guide Book on Geology of The Jos Plateau and Yankari Game Reserve. The Nigerian Mining and Geosciences Society; 27 Annual Conference and $30^{\mathrm{TH}}$ Anniversary Celebration, Jos.

Shaw, T. (1978). Nigeria, its Archaeology and Early History, Thames and Hudson, London

Van Westen, C. J. (2000). The modelling of landslide hazards using GIS. Surveys in Geophysics, 21, 241-255.

Van Westen, C. J., Castellanos, E., \& Kuriakose, S. L. (2008). Spatial data for landslide susceptibility, hazard, and vulnerability assessment: An overview. Engineering Geology, 102 (3), 112-131.

Correspondance author Email: joshuayahanna1972@gmail.com 